\title{
Structural characterization of the bglH gene encoding a beta-glucosidase-like enzyme in an endophytic Bacillus pumilus strain
}

\author{
Andréa C. Bogas ${ }^{1}$, Maria Angelica E. Watanabe ${ }^{1}$, Aneli Barbosa ${ }^{2}$, Laurival A. Vilas-Boas ${ }^{1}$, Ana C. Bonatto ${ }^{3}$, \\ Robert Dekker $^{2}$, Emanuel M. Souza ${ }^{3}$ and Maria Helena P. Fungaro ${ }^{1}$ \\ ${ }^{l}$ Centro de Ciências Biológicas, Universidade Estadual de Londrina, Londrina, PR, Brazil. \\ ${ }^{2}$ Centro de Ciências Exatas, Universidade Estadual de Londrina, Londrina, PR, Brazil. \\ ${ }^{3}$ Departamento de Bioquímica e Biologia Molecular, Universidade Federal do Paraná, Curitiba, PR, Brazil.
}

\begin{abstract}
A beta-glucosidase-like enzyme-encoding gene $(\mathrm{bg} / \mathrm{H})$ of an endophytic Bacillus pumilus strain (CL16) was cloned using a shotgun genomic library constructed in Escherichia coli. The nucleotide sequence of the entire cloned fragment (2484 bp) was determined and characterized. An incomplete open reading frame (ORF) of 534 bp (ORF1) designated $b g / P$ and a complete ORF of $1419 \mathrm{bp}$ (ORF2) designated $b g / \mathrm{H}$, located in the fragment, are organized in an operon. The protein deduced from $1419 \mathrm{bp}$ (ORF2) had 472 amino acid residues without a characteristic signal peptide sequence, suggesting that the enzyme is localized in the cytoplasm. The amino acid sequence deduced from $\mathrm{bg} / \mathrm{H}$ gene had high similarity with $\beta$-glucosidases from the glycosyl hydrolase family 1 . Over-expression of the $B$. pumilus bglH gene in $E$. coli showed a $54 \mathrm{kDa}$ protein whose identity was confirmed by mass spectrometry (MALDI-TOF).
\end{abstract}

Key words: Bacillus pumilus, bglH, glucosidase, glycosyl hydrolase 1, PTS.

Received: November 28, 2005; Accepted: August 17, 2006.

Cellulose comprises the major carbohydrate polymer of the plant cell wall. It is an unbranched polymer composed of anhydro-1,4-D-glucopyranoside units linked by $\beta$-glucosidic bonds. Enzymatic degradation of cellulose within the polysaccharide matrix of the cell wall requires the synergism of multiple enzymes such as the cellulases, exo- (cellobiohydrolase) and endo- $\beta-1,4$-glucanases, and $\beta$-glucosidases (cellobiases) (Knauf and Moniruzzaman, 2004). The $\beta$-glucosidases are widespread in microorganisms where they metabolize various carbohydrate substrates, including cellobiose, produced as a consequence of cellulose hydrolysis, and aromatic $\beta$-glucosides such as arbutin and salicin that are produced by a variety of plants (Tajima et al., 2001; Spiridonov and Wilson, 2001; Park et al., 2002; Marques et al., 2003; An et al., 2005).

Considerable polymorphism in $\beta$-glucosidase forms, functions and kinetics has been reported (Ogunseitan, 2003). Although several cellulolytic enzymes released by phytopathogens have already been well-characterized, knowledge on the uptake and hydrolysis of carbohydrates

Send correspondence to MHP Fungaro. Departamento de Biologia Geral, Centro de Ciências Biológicas, Universidade Estadual de Londrina, Caixa Postal 6001, 86100-990 Londrina, PR, Brazil. E-mail: fungaro@uel.br. by endophytic microorganisms is limited. Endophyte microorganisms colonize inner plant tissues, living symbiotically with the host species (Azevedo et al., 2000). These microorganisms have been investigated as a source of new genes and proteins for use in industrial processes (Stamford et al., 2001, 2002; Pleban et al., 1997; Reddy et al., 1996; Moy et al., 2002; Lima et al., 2004).

Recently, 15 endophytic strains of Bacillus spp. isolated from Citrus were evaluated for cellulolytic activity (Lima et al., 2004). The Bacillus pumilus strain CL16 showed high cellulase activity and was selected for further studies. We have cloned the $\beta$-1,4-endoglucanase eglA gene from strain CL16 and expressed it in E. coli. The endo-1,4- $\beta$-glucanase EglA has high thermostability, an important feature in biotechnical processes that require high temperatures (Lima et al., 2004).

During the study described in the present paper we isolated and characterized a new locus of $\beta$-glucoside sugar utilization genes from the endophytic B. pumilus CL16 strain.

Using the degenerated primers DEG1F ( $5^{\prime}$-ATRACC TACTgNAARTTRgg-3') and DEG1R (5'gCRAANCCY AgHTARACggT-3') designed based on the amino acid regions conserved amongst $\beta$-glucosidases reported for $\mathrm{Ba}$ - 
cillus spp, a $560 \mathrm{bp} \mathrm{B.} \mathrm{pumilus} \mathrm{fragment} \mathrm{was} \mathrm{obtained} \mathrm{and}$ successfully cloned in the pUC18 vector. Nucleotide sequence, determined using the DYEnamic ET DYE Terminator Cycle Sequencing Kit (Amersham Biosciences, Germany) on MegaBACE 1000 (Amersham Pharmacia Biotech, Germany), showed high similarity with the $b g l H$ gene from B. subtilis subsp. subtilis strain 168 (E value $=1 \mathrm{e}^{-17}$ ).

This fragment was successfully used as a probe for screening the $b g l H$ gene in a shotgun genomic library constructed from B. pumilus strain CL16 (Lima et al., 2004). Hybridization was done using the DIG High Prime DNA Labeling and Detection Starter Kit II, according to the manufacturer's instructions (Roche, Germany). Pre-hybridization (30 min) and hybridization (overnight) steps were at $42{ }^{\circ} \mathrm{C}$. Only one positive transformant was recovered from 2400 colonies. The recombinant plasmid isolated from this clone was denoted $\mathrm{pMH} 2$. The presence of the bglH gene was confirmed by two steps of sequencing. Firstly, using the M13 primers (Amersham Biosciences, Germany) and then with a set of new primers, GLICO1 F (5'-TCCAgAgATTCTTggACAAgT-3'), GLICO2 R (5'CACTTggAACAAATTggTgATg-3') and GLm F (5'gCATAAgCACggAATTgAgTC3-3') designed specifically for a $b g l$ internal segment.

Two open reading frames (ORF) were found to compose the insert: an incomplete ORF of $534 \mathrm{bp}(\mathrm{ORF} 1)$ and a complete one with 1419 bp (ORF2), which presented high similarity with the $b g l P$ and $b g l H$ genes, respectively, both from B. subtilis subsp. subtilis strain 168 (Kunst et al., 1997). The bglP gene from $B$. subtilis encodes an aryl- $\beta$ glucoside-specific enzyme II of the phosphoenolpyruvate sugar: phosphotransferase system (PTS), whereas the activity of $\mathrm{BglH}$ from $B$. subtilis was only recently directly demonstrated (Setlow et al., 2004). These authors showed that the $b g l H$ gene from $B$. subtilis encodes an arylphospho- $\beta$-D-glucosidase and that this gene was induced by aryl- $\beta$-D-glucosides.

The $\beta$-glucoside utilization pathways that rely upon the PTS for carbohydrate uptake have been characterized in several bacteria (Krüger and Hecker, 1995; Lai et al., 1997; Brown and Thomson, 1998; Brehm et al., 1999; Marasco et al., 1998; An et al., 2005), but not in B. pumilus. According to An et al. (2005) the discovery of new PTS-related sequences in bacterial genomes continues, and suggests that PTS enzymes might have additional unknown functions.

The nucleotide sequence of the entire insert (2484 bp) and the deduced protein sequence of the $b g l H$ gene from $B$. pumilus are shown in Figure 1. The ORF1 was upstream from ORF2, and separated by a $24 \mathrm{bp}$ sequence. The absence of a promoter sequence between the ORFs identified by us, and their similarity with the operon described for $B$. subtilis strain 168 (Entrez Gene-NCBI server) suggest that they are organized into an operon. The nucleotide sequence downstream from ORF2 was compared to other sequences

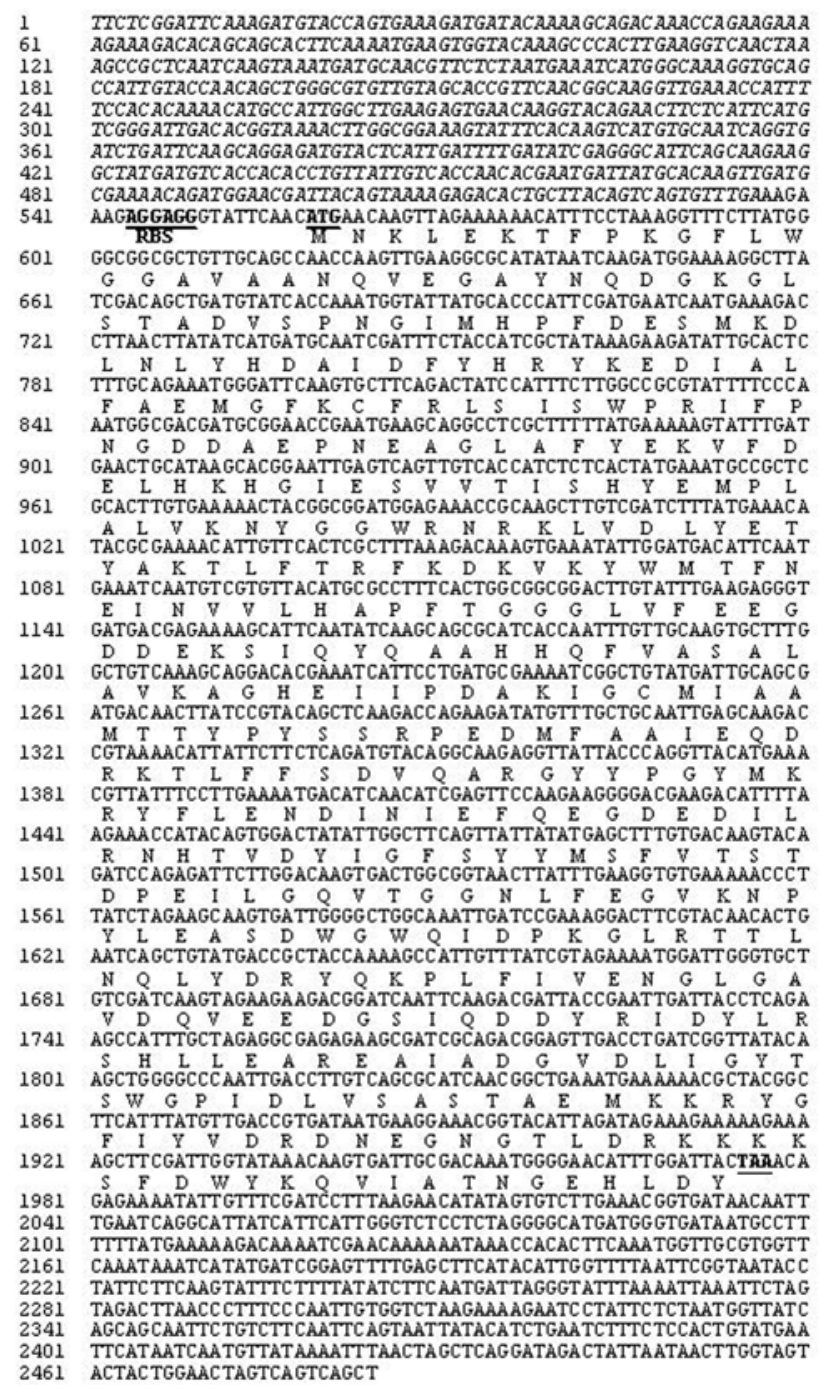

Figure 1 - Nucleotide sequence of the entire insert (2484 bp) and the deduced protein sequence of the $b g l H$ gene from Bacillus pumilus. Start and stop codons and the ribosome-bounding site (RBS) are underlined. Partial nucleotide sequence of the $b g l P$ gene is in italic font.

deposited at NCBI GenBank (BLASTX) but no similarity could be identified.

We found that the 1419-nucleotide-long ORF2 had a GC content of $41.6 \%$. It was preceded by a potential ribosome binding site (AGGAGG) that was 9 bp upstream from the putative ATG start codon but, as expected, with no adjacent promoter sequence. Downstream from the TAA stop codon, no sequence resembling a rho-independent transcriptional terminator could be identified. The protein deduced from the ORF-complete sequence had 472 amino acid residues with an estimated molecular mass of $53.9 \mathrm{kDa}$ and a isoelectric point of 4.97. The CDSearch program (NCBI server) revealed that BglH had a single domain consisting of the glycosyl hydrolase family 1 (GH1) sequence, covering 464 residues from amino acid 4 to 468 .

The deduced B. pumilus $\mathrm{BglH}$ amino acid sequence was compared to other $\mathrm{BglH}$ sequences deposited at $\mathrm{NCBI}$ 
GenBank (Figure 2) and found to be highly similar to homologous enzymes from several Bacillus species: $B$. halodurans (gi 10173219), B. subtilis strain 168 (gi 7435440), B. cereus (gi 52144364), B. thuringiensis (gi 49477027), B. licheniformis (gi 52082495), B. clausii (gi 56965550). The $\mathrm{Glu}^{175}$ and $\mathrm{Glu}^{369}$ residues, the catalytic nucleophile, conserved in the B. pumilus $\mathrm{BglH}$, are characteristic of family 1 proteins that hydrolyze glucosidic bonds by acid/base catalysis (Withers and Aebersold, 1995).

The absence of a signal peptide sequence (SignalP 3.0 program) and the lack of potential transmembrane regions (TMPred program) in the BglH sequence suggest that the enzyme is localized in the cytoplasm, as is the case for most bacterial $\beta$-glucosidases (Bhatia et al., 2002 and references therein).

We constructed an expression plasmid for the overproduction of $\beta$-glucosidase ( $\mathrm{Bgl}$ ) by amplifying the $b g l$ open reading frame (ORF) using the polymerase chain reaction (PCR) and the MHF (5'-CACCATgAACAAgTT AgAAAAAACAT-3') and MHR (5'-TTAgTAATCCAA ATgTTCCCCATTTg5-3') primer pair. For DNA polymerization the AccuPrime $P f x$ enzyme (Invitrogen, USA) was used. The amplified product was cloned into the pENTR/ $\mathrm{SD} / \mathrm{D}-\mathrm{TOPO}$ plasmid producing the entry vector of the Gateway Cloning System (Invitrogen, USA). From the entry vector the $b g l$ gene was transferred to the expression vector pET-DEST42 by in vitro site-specific recombination. The recombinant expression plasmid containing the bgl gene was named the pAB1 plasmid. The cloned fragment was completely sequenced to confirm that no mutations were introduced during the amplification procedures.

Transformed Escherichia coli BL21 CodonPlus (DE3) cells harboring the $\mathrm{pAB} 1$ expression vector were grown on Luria-Bertani medium (LB) supplemented with $250 \mu \mathrm{g} \mathrm{mL}^{-1}$ ampicillin and incubated at $37^{\circ} \mathrm{C}$ until the log phase $\left(\mathrm{OD}_{600 \mathrm{~nm}}=0.2\right)$. After induction with $0.5 \mathrm{mmol} \mathrm{L}^{-1}$ IPTG (isopropyl-beta-D-thiogalactopyranoside) a strong band of $54 \mathrm{kDa}$ was detected by sodium dodecyl sulfate polyacrylamide gel electrophoreses (SDS-PAGE) analysis (Laemmli, 1970), suggesting the over-expression of the $B$. pumilus bglH gene in E. coli (Figure 3). This molecular mass is consistent with that predicted from the amino acid sequence of the BglH protein. The over-expressed protein was completely purified and subjected to digestion with trypsin followed by peptide fingerprint analysis by matrix assisted laser desorption ionization time-of-flight mass spectrometry (MALDI-TOF/MS), in order to confirm the protein identity. The provided peptide masses were equivalent to the ones predicted, confirming that the overexpressed $54 \mathrm{kDa}$-band was in fact the $\mathrm{BglH}$ protein of $B$. pumilus.

Crude protein extracts obtained from the $E$. coli cells harboring the pAB1 plasmid were assayed for activity against $\rho$-nitrophenyl- $\beta$-D-glucopyranoside and cellobiose. Each assay consisted of $0.5 \mathrm{~mL} 5 \mathrm{mM}$ of $\rho$-nitro-
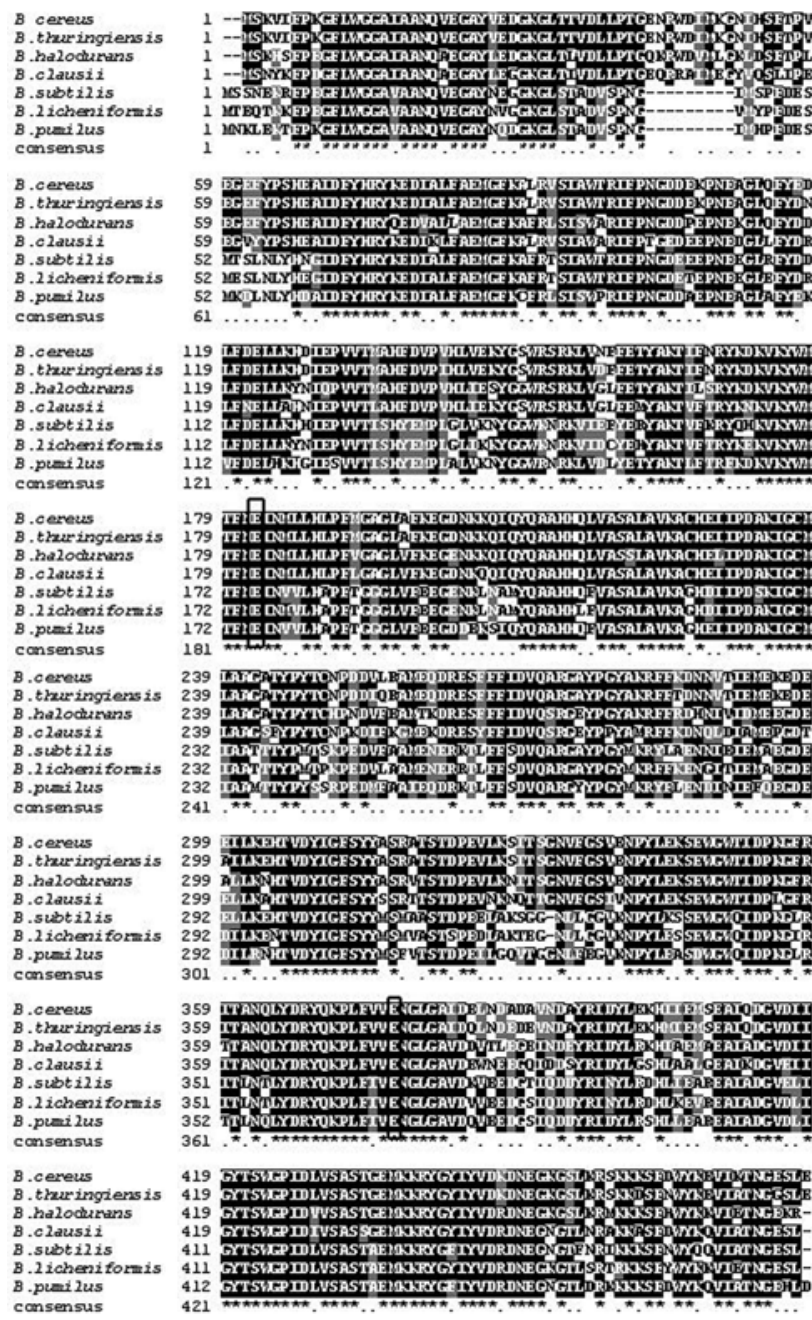

Figure 2 - Multiple alignment of amino acid sequence predicted from $b g l \mathrm{H}$ genes of the following Bacillus species: B, halodurans (gi 10173210); B. subtilis strain 168 (gi 7435440); B. cereus (gi 52144364); B. thuringiensis (gi 49477027); B. licheniformis (gi52082495); B. clausii (gi 56965550); and B. pumilus obtained in the present study. Asterisks show amino acids conserved in all sequences analyzed. The regions of catalytic amino acid residue $\mathrm{Glu}^{175}$ and the catalytic nucleophile $\mathrm{Glu}^{369}$ are boxed.

phenyl- $\beta$-D-glucopyranoside or $0.2 \%$ of cellobiose as substrate, $0.1 \mathrm{~mL}$ of $50 \mathrm{mM}$ phosphate buffer ( $\mathrm{pH} 5.8$ to 7.5 ) or Mc'Ilvaine buffer ( $\mathrm{pH} 3$ to 7 ) and $0.05 \mathrm{~mL}$ of crude enzyme. The mixture was incubated for $1 \mathrm{~h}$ at $37^{\circ} \mathrm{C}$ and the activity of $\beta$-glucosidase towards $\rho$-nitrophenyl- $\beta$-D-glucopyranoside was estimated by measuring the amount of $\rho$-nitrophenol released at $400 \mathrm{~nm}$. The activity of $\beta$-glucosidase toward cellobiose was estimated by measuring the glucose released by the glucose oxidase method (Glucose Enzyme Color Kit, Bio Diagnostica, Brazil). The enzymatic activity of $\mathrm{Bgl}$ against $\rho$-nitrophenyl- $\beta$-D-glucopyranoside was assayed in Mc'Ilvaine buffer ( $\mathrm{pH}$ 7.0) using the same protocol. Little activity against synthetic aryl- $\beta$-D-glucosides and no activity against cellobiose were observed. The highest activity against $\rho$-nitrophenyl- $\beta$-D- 


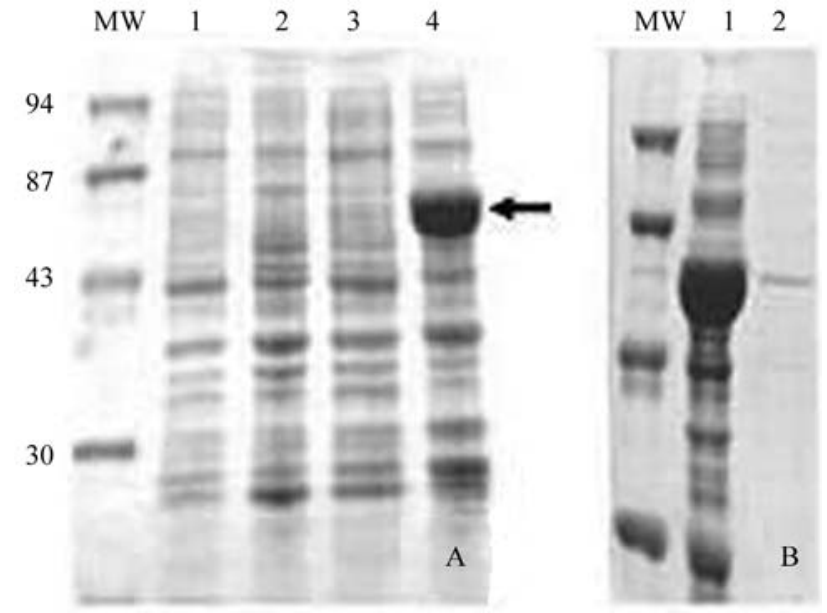

Figure 3 - Over-expression of the BglH protein in Escherichia coli BL21 CodonPlus(DE3) was analyzed by $12 \%$ SDS-PAGE. Proteins were stained with Coomassie Blue R-250. a) Lane 1, lysate from untransformed cells not induced with IPTG; Lane 2, lysate from untransformed cells induced with IPTG; Lane 3, lysate from transformed cells with pAB1 not induced with IPTG; Lane 4, lysate from transformed cells with pAB1 induced with IPTG. b) Lane 1, lysate from transformed cells with pAB1 induced with IPTG; Lane 2, Purified protein obtained from transformed cells with pAB1. Molecular weight markers (MW) are indicated in $\mathrm{kDa}$. Arrow indicates the $\mathrm{BglH}$ protein.

glucopyranoside $\left(0.106 \mu \mathrm{mol} \mathrm{min}^{-1} \mathrm{~mL}^{-1}\right)$ was observed using Mc'Ilvaine buffer at $\mathrm{pH}$ 7.0. This low activity was also observed using purified Bgl. The B. subtilis BglH also showed very low activity against non-phosphorylated $\beta$-glucosides. The enzyme activity against aryl-phospho- $\beta$-D-glucosides was not measured because there was no commercial supplier for this substrate.

\section{Acknowledgments}

We would like to thank Dr. Fábio de Oliveira Pedrosa (GENOPAR Consortium Coordinator) for providing us with laboratory facilities. This work was partially supported by the Brazilian agency Conselho Nacional de Desenvolvimento Científico e Tecnológico ( $\mathrm{CNPq})$. A.C. Bogas is grateful to the Brazilian agency Coordenação de Aperfeiçoamento de Pessoal de Nível Superior (CAPES) for a scholarship.

\section{References}

An CL, Lim WJ, Hong SY, Shin EC, Kim MK, Lee JR, Park SR, Woo JG, Lim YP and Yun HD (2005) Structural and biochemical analysis of the asc operon encoding 6-phosphobeta-glucosidase in Pectobacterium carotovorum subsp. carotovorum LY34. Res Microbiol 156:145-153.

Azevedo JL, Maccheroni Jr W, Pereira JO and Araújo WL (2000) Endophytic microorganisms: A review on insect control and recent advances on tropical plants. Eletron J Biotechnol 3:40-65.
Bhatia Y, Misha S and Bisaria VS (2002) Microbial B-glucosidases: Cloning, properties and applications. Crit Rev Biotechnol 22:375-407.

Brehm K, Ripio MT, Kreft J and Vazquez-Boland JA (1999) The bvr locus of Listeria monocytogenes mediates virulence gene repression by $\beta$-glucosides. J Bacteriol 181:50245032 .

Brown GD and Thomson JA (1998) Isolation and characterization of an aryl- $\beta$-D-glucoside uptake and utilization system (abg) from the gram-positive ruminal Clostridium species $C$. longisporium. Mol Gen Genet 257:213-218.

Knauf M and Moniruzzaman M (2004) Lignocellulosic biomass processing: A perspective. Int Sugar J 106:147-150.

Kunst F, Ogasawara N, Moszer I, Albertini AM, Alloni G, Azevedo $\mathrm{V}$, Bertero MG, Bessieres P, Bolotin A, Borchert S, Borris R, Boursier L, Brans M, Brignell SC, Bron S, Brouillet S, Bruschi CV, Cladwell B, Capuano V, Carter NM, Choi SK, Codani JJ, Connerton IF, Danchin A, et al (1997) The complete genome of the gram-positive bacterium Bacillus subtilis. Nature 6657:249-256.

Krüger S and Hecker M (1995) Regulation of the putative $b g l \mathrm{PH}$ operon for aryl- $\beta$-glucoside utilization in Bacillus subtilis. J. Bacteriol 177:5590-5597.

Laemmli UK (1970) Cleavage of structural proteins during the assembly of the head of bacteriophage T7. Nature 227:680685.

Lai X, Davis FC, Hespell RB and Ingram LO (1997) Cloning of cellobiose phosphoenolpyruvate-dependent phosphotransferase genes: Functional expression in recombinant Escherichia coli and identification of a putative binding region for disaccharides. Appl Environ Microbiol 63:355-363.

Lima AOS, Quecine MC, Fungaro MHP, Andreote FD, Maccheroni W Jr, Araujo WL, Silva-Filho MC, Pizzirani-Kleiner AA and Azevedo JL (2004) Molecular characterization of a $\beta$-1,4-endoglucanase from an endophytic Bacillus pumilus strain. Appl Microbiol Biotechnol 68:57-65.

Marasco R, Muscariello L, Varcamonti M, De Felice M and Sacco M (1998) Expression of the $b g l \mathrm{H}$ gene of Lactobacillus plantarum is controlled by carbon catabolite repression. $\mathrm{J}$ Bacteriol 180:3400-3404.

Marques AR, Coutinho PM, Videira P, Fialho AM and Sá-Correia I (2003) Sphingomonas paucimobilis $\beta$-glucosidase Bgl1: A member of a new bacterial subfamily in glycoside hydrolase family 1. Biochem J 370:793-804.

Moy M, Li HM, Sullivan R, White Jr. JF and Belanger FC (2002) Endophytic fungal $\beta$-1,6-glucanase expression in the infected host grass. Plant Physiol 130:1298-1308.

Ogunseitan AO (2003) Biotechnology and industrial ecology: New challenges for a changing global environment. Afr J Biotechnol 2:596-601.

Park JK, Wang LX, Patel HV and Roseman S (2002) Molecular cloning and characterization of a unique $\beta$-glucosidase from Escherichia coli. J Biol Chem 277:29555-29560.

Pleban S, Chernin L and Chet I (1997) Chitinolytic activity of an endophytic strain of Bacillus cereus. Lett Appl Microbiol 25:284-288.

Reddy PV, Lam CK and Belanger FC (1996) Mutualistic fungal endophytes express a proteinase that is homologous to proteases suspected to be important in fungal pathogenicity. Plant Physiol 111:1209-1218. 
Stamford TL, Stamford NP, Coelho LC and Araujo JM (2001) Production and characterization of a thermostable alphaamylase from Nocardiopis sp. endophyte of yam bean. Bioresour Technol 76:137-141.

Stamford TL, Stamford NP, Coelho LC and Araujo JM (2002) Production and characterization of a thermostable glucoamylase from Streptosporangium sp. endophyte of maize leaves. Bioresour Technol 83:105-109.

Setlow B, Cabrera-Hernandez A, Cabrera-Martinez RM and Setlow P (2004) Identification of aryl-phospho- $\beta$-D-glucosidases in Bacillus subtilis. Arch Microbiol 181:60-67.
Spiridonov NA and Wilson DB (2001) Cloning and biochemical characterization of $\mathrm{BglC}$, a $\beta$-glucosidase from the cellulolytic actinomycete Thermobifida fusca. Curr Microbiol 42:295-301.

Tajima K, Nakajima K, Yamashita H, Shiba T, Munekata M and Takai M (2001) Cloning and sequencing of the beta-glucosidase gene from Acetobacter xylinun ATCC 23769. DNA Res 8:263-269.

Withers SG and Aebersold R (1995) Approaches to labeling and identification of active site residues in glycosidases. Protein Sci 4:361-372.

Associate Editor: Luis Carlos de Souza Ferreira 